\title{
Ceramide Expression and Cell Homeostasis in Chronic Obstructive Pulmonary Disease
}

\author{
Maria C. Scarpa ${ }^{a}$ Simonetta Baraldo $^{b}$ Emanuela Marian $^{a}$ Graziella Turato $^{b}$ \\ Fiorella Calabrese ${ }^{c}$ Marina Saetta $^{b}$ Piero Maestrelli $^{a}$ \\ Departments of a Environmental Medicine and Public Health, ${ }^{b}$ Cardiologic, Thoracic and Vascular Sciences and \\ 'Medical Diagnostic Sciences and Special Therapies, University of Padova, Padova, Italy
}

\section{Key Words}

Chronic obstructive pulmonary disease clinical/basic investigations - Emphysema - Histopathology $\cdot$ Tobacco smoking $\cdot$ Lung

\section{Abstract}

Background: Increased expression of ceramide has been detected in emphysema. Ceramide promotes autophagy and apoptosis, which concur with cellular homeostasis. $\mathbf{O b}$ jectives: To determine whether ceramide expression is associated with the development of chronic obstructive pulmonary disease (COPD) and with altered cellular homeostasis in lung parenchyma. Methods: We studied 10 subjects with severe COPD, 13 with mild/moderate COPD, 11 with idiopathic pulmonary fibrosis (IPF), 12 non-COPD smokers, and 11 nonsmoking controls. The immunoreactivity for ceramide along with markers of autophagy (LC3B), apoptosis (cleaved caspase-3), and cell proliferation (MIB1) was quantified in alveolar walls. Results: Ceramide expression was increased in COPD patients compared with control smokers and was related to the impairment of gas exchange but not to the degree of airflow limitation. In COPD, an important activation of apoptosis and autophagy pathways was observed, par- ticularly in patients with severe disease, that was not counterbalanced by cell proliferation. Upregulation of ceramide was observed even in subjects with IPF in whom activation of apoptosis and autophagy was negligible and cell proliferation was instead the most prominent feature. Conclusions: Ceramide expression, which is increased in COPD and even more so in IPF, appears to be neither specific nor related to COPD severity, probably representing a broader marker of lung damage. In contrast, apoptosis and autophagy are characteristics of the COPD pathology, particularly in its most severe stage.

Copyright $\odot 2012$ S. Karger AG, Basel

\section{Introduction}

Several mechanisms have been considered in the pathogenesis of chronic obstructive pulmonary disease (COPD), including imbalance between protease and antiprotease activities, oxidative stress, age-related alterations, infections, and autoimmunity [1].

In animal models of emphysema caused by vascular endothelial growth factor (VEGF) receptor inhibition, the development of the disease was dependent on lung

\section{KARGER}

Fax +4161306 1234

E-Mail karger@karger.com

www.karger.com
(C) 2012 S. Karger AG, Basel

0025-7931/13/0854-0342\$38.00/0

Accessible online at: www.karger.com/res
Prof. Piero Maestrelli

Dipartimento di Medicina Ambientale e Sanità Pubblica

Università degli Studi di Padova

Via Giustiniani 2, IT-35128 Padova (Italy)

E-Mail piero.maestrelli@unipd.it 
ceramide [2]. The study reported that increased lung ceramide levels also occurred in the lungs of emphysema patients, suggesting that ceramide upregulation might be important in the pathogenesis of emphysema in humans. Ceramide is a sphingolipidic second messenger that promotes autophagy and apoptosis [3]. Autophagy is a highly regulated process that, depending on the cellular settings, can constitute a stress adaptation that avoids cell death or can constitute an alternative celldeath pathway. Several studies in vitro [4-6] have proven that ceramide triggers autophagy downregulating nutrient transporter proteins. Works by Li et al. [7] and Daido et al. [8] reported ceramide-induced cell death through autophagy, either by targeting mitochondria or by increasing the rate of autophagy by upregulating the expression of Beclin-1. In the context of COPD, it has been proposed that autophagy can contribute to its pathogenesis by promoting epithelial cell death [9]. However, since relatively few studies have been done on the lung, the functional significance of autophagy in human pulmonary disease remains largely unknown. Apoptosis of structural cells in the lung has been investigated more extensively. Indeed, apoptosis is generally accepted as an important upstream event in the pathogenesis of COPD and pulmonary emphysema [10], but there are issues that need to be further explored. In fact, in previous investigations it has not been thoroughly addressed whether apoptosis was related to the severity of functional impairment. Moreover, it is not clear whether the smoking habit had a role in inducing apoptosis independently of airflow limitation, since often the smoking status of the control population was unknown [11-13] or was significantly different from that of the COPD subjects $[14,15]$.

Our aims were to determine whether ceramide expression is associated with the development of chronic airflow limitation induced by cigarette smoking and with altered cellular homeostasis in lung parenchyma of subjects with COPD. Moreover, we investigated whether ceramide and markers of autophagy (LC3B), apoptosis (caspase-3), and cell proliferation (MIB1) in the lung are specific for COPD by comparison with another chronic lung disease characterized by progressive loss of lung function, i.e. idiopathic pulmonary fibrosis (IPF). The immunoreactivity for ceramide, LC3B, cleaved caspase-3, and MIB1 was quantified in the alveolar walls of lung specimens from 11 nonsmoking subjects, 12 smokers without COPD, 23 smokers with COPD of differing severity, and 11 subjects with IPF.

\section{Methods}

\section{Subjects}

Four groups of subjects undergoing lung resection for treatment of a solitary peripheral carcinoma or lung volume reduction surgery for treatment of emphysema were examined. The groups were divided as follows: 10 subjects with a smoking history of at least 15 pack-years and severe COPD defined according to the GOLD definition [16] (GOLD III-IV), 13 subjects with a smoking history of at least 15 pack-years and mild-to-moderate COPD (GOLD I-II), 12 asymptomatic smokers with a smoking history of at least 15 pack-years and normal lung function (smokers without COPD), and 11 asymptomatic nonsmoking subjects with normal lung function. Pulmonary function tests were performed within the week before the patients underwent surgery and included spirometry and arterial blood gas analysis. COPD subjects had no exacerbations during the month preceding the study. All of the subjects had been free of acute upper respiratory tract infections, and none had received oral glucocorticoids or antibiotics within the month preceding surgery. They had negative skin test results for common allergen extracts and no history of asthma or allergic rhinitis. In addition, we examined explanted lung specimens of 11 subjects with IPF and a smoking history of at least 15 pack-years who exhibited a reduction in $\mathrm{FEV}_{1}$ and in arterial oxygen partial pressure $\left(\mathrm{PaO}_{2}\right)$ comparable to that of severe COPD.

The study conformed to the Declaration of Helsinki, and informed written consent was obtained for each subject. The Local Research Ethics Committee approved the study.

\section{Lung Tissue Analysis}

Tissue blocks taken from the subpleural parenchyma, avoiding areas involved by tumor, were fixed in $4 \%$ formaldehyde and embedded in paraffin as described elsewhere [17]. Sections that were $5 \mu \mathrm{m}$ thick were cut for immunohistochemical analysis.

All lung sections were subjected to antigen retrieval by heating in a microwave oven on high power for $10 \mathrm{~min}$ in $0.01 \mathrm{~mol} / 1$ citrate buffer ( $\mathrm{pH}$ 6.0) and then incubated with a mouse monoclonal anti-ceramide primary antibody (Alexis Biochemicals, San Diego, Calif., USA; dilution 1:25 in Trizma maleate buffer), with rabbit polyclonal antibody against cleaved caspase-3 (Cell Signaling Technologies, Danvers, Mass., USA; dilution 1:200 in phosphatebuffered saline solution) and mouse monoclonal MIB-1 antibody (Dako, Santa Barbara, Calif., USA; dilution 1:50), which recognizes the Ki-67 antigen in paraffin-embedded tissue sections. Bound monoclonal anti-ceramide antibody was detected with phosphatase alkaline/antiphophatase alkaline (APAAP System K670; Dako), developed with Fast-Red (Dako), and counterstained with Mayer's hematoxylin (fig. 1). The detection system for MIB-1 was the Vectastain ABC kit (Vector, Peterborough, UK) with a mixture of 3,3'-diaminobenzidine tetra hydrochloride (Dako) and hydrogen peroxide as the chromogenic substrates, counterstained with Mayer's hematoxylin.

Polyclonal anti-cleaved caspase-3 (fig. 2) and anti-LC3B (fig. 3) antibodies were detected with avidin-biotynlated horseradish peroxidase, developed with DAB (ABC Staining System; Santa Cruz Biotechnologies, San Diego, Calif., USA), and counterstained with thiazine dye ( $1.1 \mathrm{~g} / \mathrm{l}$ in PBS $\mathrm{pH}$ 6.6).

Quantification of ceramide-, cleaved caspase-3-, LC3B-, and MIB1-positive cells was restricted to the alveolar wall as described by Saetta et al. [17]. Briefly, images for each lung section were ac- 
Fig. 1. Immunohistochemistry studies of human lung specimens are shown. Alveolar wall stained for ceramide in a patient with severe COPD (a), in a mild/moderate COPD subject (b), in a healthy smoker (c), and in a nonsmoker (d). Arrows indicate positive cells (original $\times 630$ ).
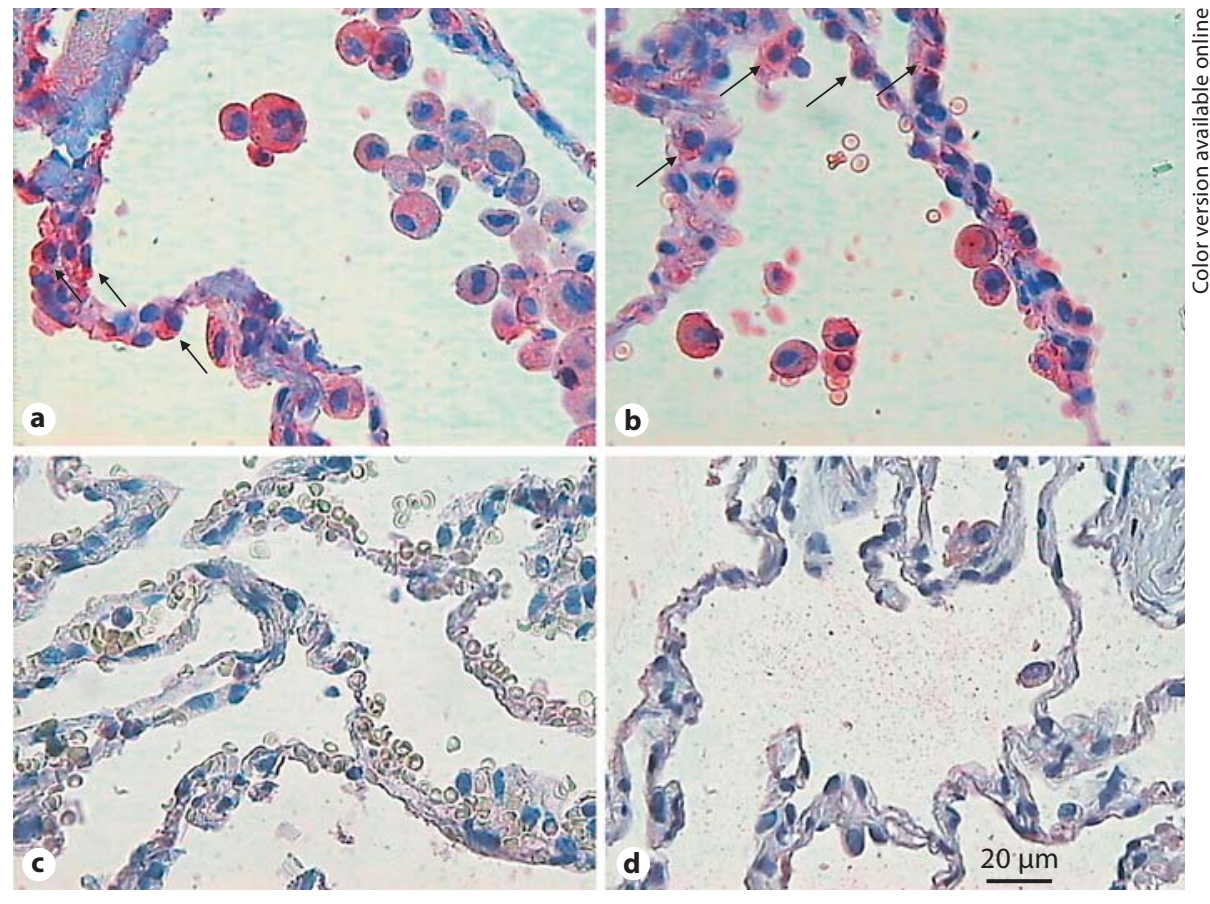

Fig. 2. Immunohistochemistry studies of apoptosis in human lung specimens are shown. Alveolar wall stained for cleaved caspase- 3 in a patient with severe COPD (a), in a mild/moderate COPD subject (b), in a healthy smoker (c), and in a nonsmoker (d). Arrows indicate positive cells (original $\times 630)$.
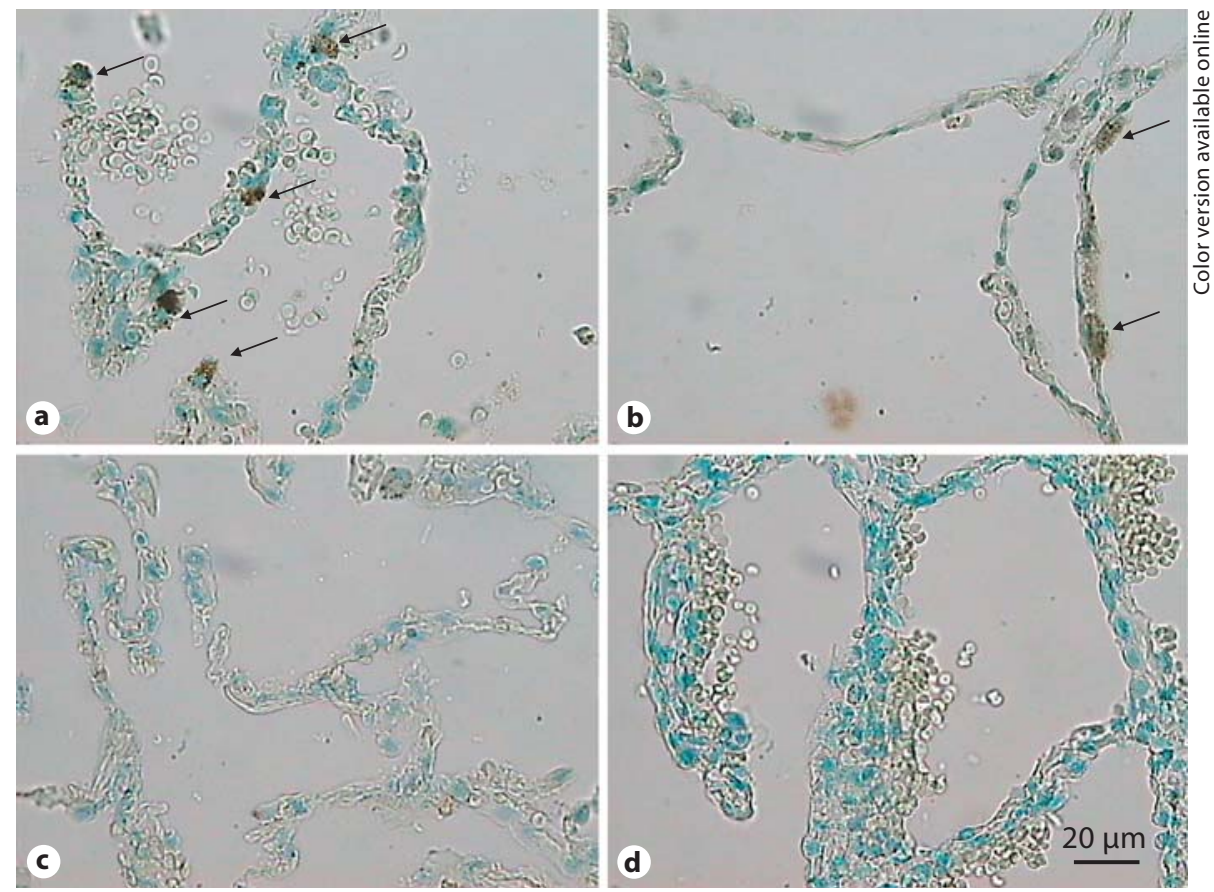

quired with a $\times 63$ lens. The number of positively stained cells within the alveolar walls was computed using a light microscope (Leica DMLB; Leica, Cambridge, UK) connected to a video recorder which was linked to a computerized image system (Casti Imaging software; SC Processing, Italy). In each case at least 10 microscopic randomly chosen fields were counted and the values were expressed as numbers of positively stained cells per millimeter of alveolar wall. The histological sample quality was not suit- able for analysis in 5 cases for ceramide staining, in 2 cases for cleaved caspase- 3 staining, and in 6 cases for LC3B staining.

\section{Statistical Analysis}

To avoid observer bias, the cases were coded and measurements were made without knowledge of clinical data. Differences between groups were analyzed using analysis of variance for clinical data and the Kruskall-Wallis test for histological data. The $\chi^{2}$ 
Fig. 3. Immunohistochemistry studies of autophagy in human lung specimens are shown. Alveolar wall stained for LC3B in a patient with COPD (a), in a mild/moderate COPD subject (b), in a healthy smoker (c), and in a nonsmoker (d). Arrows indicate positive cells (original $\times 630$ ).
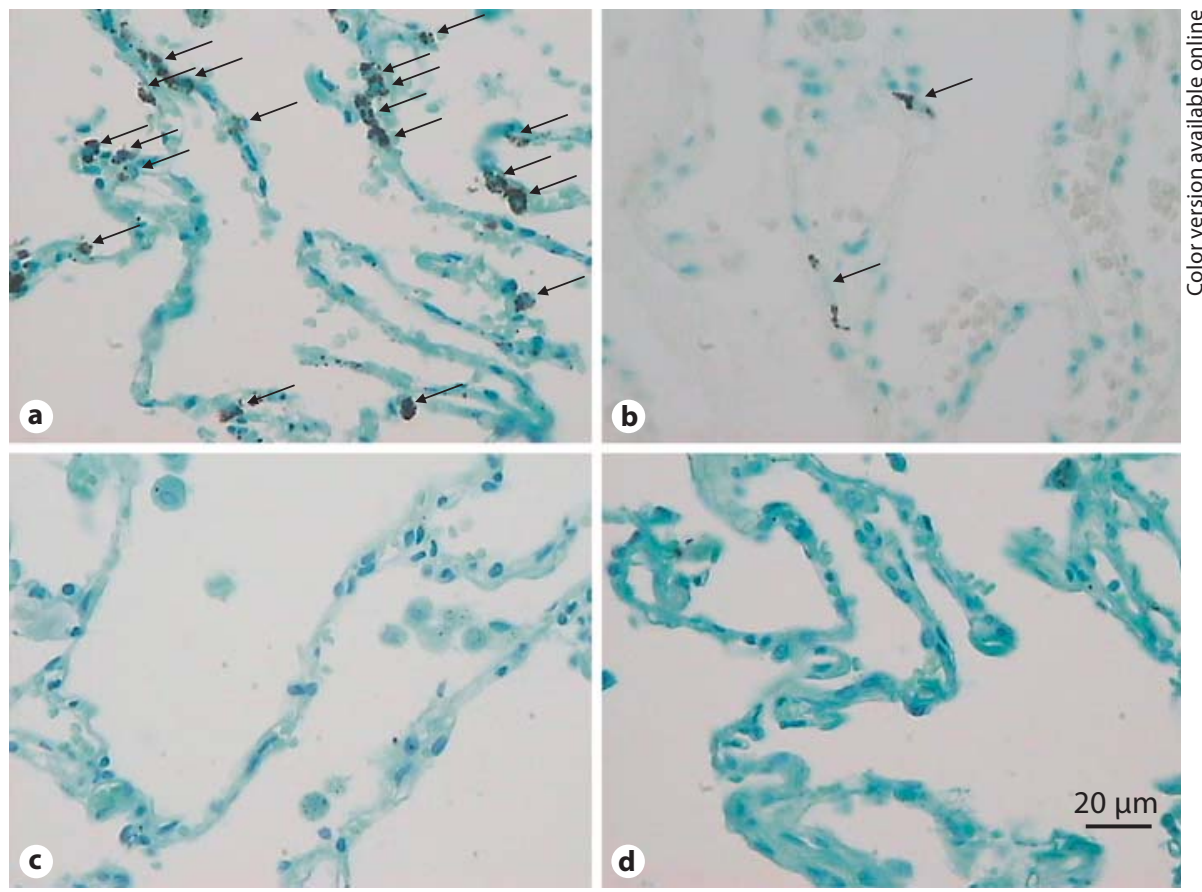

test was used to compare percentages of subjects expressing MIB1. The Mann-Whitney U test was carried out after the Kruskal-Wallis test, when appropriate. Correlation coefficients were calculated using Spearman's rank method. $\mathrm{p}<0.05$ was considered statistically significant.

\section{Results}

Table 1 shows the characteristics of the subjects examined. COPD patients, smokers without COPD, and nonsmoking controls were similar with regard to age. There was no significant difference in smoking history between smokers with or without COPD. As expected from the selection criteria, subjects with COPD had significantly lower values of $\mathrm{FEV}_{1}$ percent predicted and the $\mathrm{FEV}_{1}$ / FVC ratio compared with smokers with normal lung function and nonsmokers. IPF subjects were younger $(\mathrm{p}<0.05)$ and had smoked less $(\mathrm{p}<0.05)$ than the others four groups, but they showed lung function and $\mathrm{PaO}_{2} \mathrm{im}-$ pairment similar to those of severe COPD.

Immunostaining for ceramide was detected in alveolar macrophages and alveolar walls. The number of ceramide-positive cells in the alveolar wall was significantly increased both in severe COPD (median 3.7 cells $/ \mathrm{mm}$, IQR 2.9-5, $\mathrm{p}=0.001$ ) and in mild/moderate COPD subjects (median 3.1 cells $/ \mathrm{mm}$, IQR $2.3-4.3$, p < 0.05) compared with smokers without COPD (median 1.3 cells/ $\mathrm{mm}$, IQR 0.8-1.5). Furthermore, immunostaining for ceramide was increased both in severe COPD $(\mathrm{p}<0.05)$ and in mild/moderate COPD subjects $(\mathrm{p}<0.05)$ compared with nonsmokers (median 1.6 cells/mm, IQR $0.6-$ 2.5). No significant differences in alveolar wall expression of ceramide were observed between smokers without COPD and nonsmokers or between severe and mild/ moderate COPD subjects (table 2).

Apoptotic cells, as detected by immunohistochemistry with cleaved caspase-3 antibody, were mainly observed in the alveolar walls. Expression of cleaved caspase-3 in alveolar wall cells was significantly increased in severe COPD (median 0.9 cells $/ \mathrm{mm}$, IQR 0.4-1.6) compared with mild/moderate COPD subjects (median 0.2 cells/mm, IQR 0.1-0.6, p < 0.05), smokers without COPD (median 0.2 cells $/ \mathrm{mm}, \mathrm{IQR} 0.1-0.5, \mathrm{p}<0.05$ ), and nonsmokers (median 0.1 cells $/ \mathrm{mm}$, IQR $0.0-0.2$, p < 0.001). Mild/moderate COPD subjects had augmented cleaved caspase-3-positive cells in the alveolar wall compared with nonsmokers $(\mathrm{p}<0.05)$. No significant differences in alveolar wall expression of cleaved caspase-3 were observed between smokers without COPD and nonsmokers or between mild/moderate COPD subjects and smokers without COPD (table 2).

Autophagy, as detected by LC3B immunoreactivity, was observed in alveolar macrophages and cells of alveolar walls. The number of LC3B-positive cells in the alveo- 
Table 1. Clinical and functional characteristics of subjects

\begin{tabular}{|c|c|c|c|c|c|}
\hline & $\begin{array}{l}\text { Non- } \\
\text { smokers }\end{array}$ & $\begin{array}{l}\text { Smokers } \\
\text { without } \\
\text { COPD }\end{array}$ & $\begin{array}{l}\text { Mild/moder- } \\
\text { ate COPD } \\
\text { subjects }\end{array}$ & $\begin{array}{l}\text { Severe } \\
\text { COPD } \\
\text { subjects }\end{array}$ & IPF subjects \\
\hline \multicolumn{6}{|l|}{ Subjects, $\mathrm{n}$} \\
\hline Male & 3 & 12 & 12 & 7 & 6 \\
\hline Female & 8 & - & 1 & 3 & 5 \\
\hline Age, years & $61 \pm 5$ & $63 \pm 2$ & $65 \pm 2$ & $63 \pm 3$ & $54 \pm 2^{*}$ \\
\hline \multicolumn{6}{|l|}{ Smoking history } \\
\hline Ex-smokers, \% & - & 5 & 3 & 4 & 0 \\
\hline Packs/year & - & $41 \pm 6$ & $53 \pm 6$ & $49 \pm 10$ & $20 \pm 6^{\dagger, \neq}$ \\
\hline $\mathrm{FEV}_{1}, \%$ predicted & $106 \pm 6$ & $103 \pm 3$ & $72 \pm 4^{\S \subseteq}$ & $33 \pm 3^{\S}$ & $39 \pm 4^{\S}$ \\
\hline $\mathrm{FEV}_{1} / \mathrm{FVC}, \%$ & $82 \pm 2$ & $78 \pm 2$ & $63 \pm 1^{\$ S}$ & $36 \pm 4^{\dagger}$ & $89 \pm 2^{* *}$ \\
\hline $\mathrm{PaO}_{2}, \mathrm{~mm} \mathrm{Hg}$ & $88 \pm 5$ & 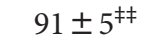 & $80 \pm 1$ & $65 \pm 5^{\dagger \dagger}$ & $61 \pm 4^{\dagger \dagger}$ \\
\hline
\end{tabular}

Values are expressed as means \pm SEM. ${ }^{*} \mathrm{p}<0.05$ vs. nonsmokers, smokers without COPD, mild/moderate COPD subjects, and severe COPD subjects. ${ }^{\dagger} \mathrm{p}<0.001$ vs. mild/moderate COPD subjects. ${ }^{\ddagger} \mathrm{p}<0.05$ vs. severe COPD subjects and smokers without COPD. ${ }^{\S} \mathrm{p}<0.05$ vs. nonsmokers and smokers without COPD. ${ }^{\$ \S} \mathrm{p}<0.001$ vs. severe COPD subjects, nonsmokers, and smokers without COPD. ${ }^{* *} \mathrm{p}<0.05$ vs. smokers without COPD. ${ }^{{ }^{+\dagger}} \mathrm{p}<0.05$ vs. nonsmokers, smokers without COPD, and mild/moderate COPD subjects. ${ }^{\ddagger \ddagger} \mathrm{p}<0.05$ vs. mild/ moderate COPD subjects.

Table 2. Expression of ceramide and markers of apoptosis (cleaved caspase-3), autophagy (LC3B), and cell proliferation (MIB1) (number of positive cells/mm of alveolar wall)

\begin{tabular}{|c|c|c|c|c|}
\hline & Nonsmokers & $\begin{array}{l}\text { Smokers without } \\
\text { COPD }\end{array}$ & $\begin{array}{l}\text { Mild/moderate } \\
\text { COPD subjects }\end{array}$ & $\begin{array}{l}\text { Severe COPD } \\
\text { subjects }\end{array}$ \\
\hline Ceramide & $1.60(0.57-2.50)$ & $1.30(0.80-1.50)$ & $3.05(2.30-4.30)^{*}$ & $3.70(2.90-5.00)^{\dagger, \neq}$ \\
\hline Cleaved caspase- 3 & $0.14(0-0.16)$ & $0.19(0.14-0.47)$ & $0.24(0.12-0.62)^{\ddagger}$ & $0.88(0.42-1.56)^{\S, \S \S}$ \\
\hline LC3B & $0(0-0)$ & $0(0-0.39)$ & $0.26(0-0.50)^{\ddagger}$ & $0.88(0.44-1.04)^{* *}$ \\
\hline MIB1 & $0(0-0)$ & $0(0-0.17)$ & $0(0-0.22)$ & $0(0-0.20)$ \\
\hline
\end{tabular}

Values are expressed as medians (IQR). ${ }^{*} \mathrm{p}<0.05$ vs. nonsmokers and smokers without COPD. ${ }^{\dagger} \mathrm{p}<0.001$ vs. smokers without COPD. ${ }^{\ddagger} \mathrm{p}<0.05$ vs. nonsmokers. ${ }^{\S} \mathrm{p}<0.05$ vs. mild/moderate COPD subjects and smokers without COPD. ${ }^{\S \S} \mathrm{p}<0.001$ vs. nonsmokers. ${ }^{* *} \mathrm{p}<0.05$ vs. mild/moderate COPD subjects, nonsmokers, and smokers without COPD.

lar wall was significantly increased in severe COPD (median 0.88 cells/mm, IQR $0.44-1.04, \mathrm{p}=0.05)$ compared with mild/moderate COPD subjects (median 0.26 cells/ $\mathrm{mm}$, IQR $0-0.5$ ), smokers without COPD (median 0 cells/ $\mathrm{mm}$, IQR 0-0.39), and nonsmokers (median 0 cells $/ \mathrm{mm}$, IQR 0-0). Furthermore, immunostaining for LC3B was increased in mild/moderate COPD subjects $(\mathrm{p}<0.05)$ compared with nonsmokers, who did not express at all LC3B in the alveolar wall (table 2). No significant differences in ceramide, caspase-3, and LC3B expression were observed between ex-smokers and current smokers.
When the subjects in table 2 were analyzed as one group, the expression of ceramide was directly related to the numbers of cleaved caspase $-3^{+}$cells ( $\mathrm{rho}=0.32 ; \mathrm{p}=$ 0.05 ) and $\mathrm{LC}_{3} \mathrm{~B}^{+}$cells (rho $=0.39 ; \mathrm{p}=0.02$ ). The number of ceramide-positive cells was inversely correlated with $\mathrm{PaO}_{2}$ in the groups of smokers ( $\mathrm{rho}=-0.42 ; \mathrm{p}=0.037$ ).

To evaluate whether ceramide upregulation was specific for the lung damage associated with COPD, we then examined its expression in a different chronic lung disease, IPF. We found that the IPF subjects had significantly higher ceramide expression in the lung parenchyma 


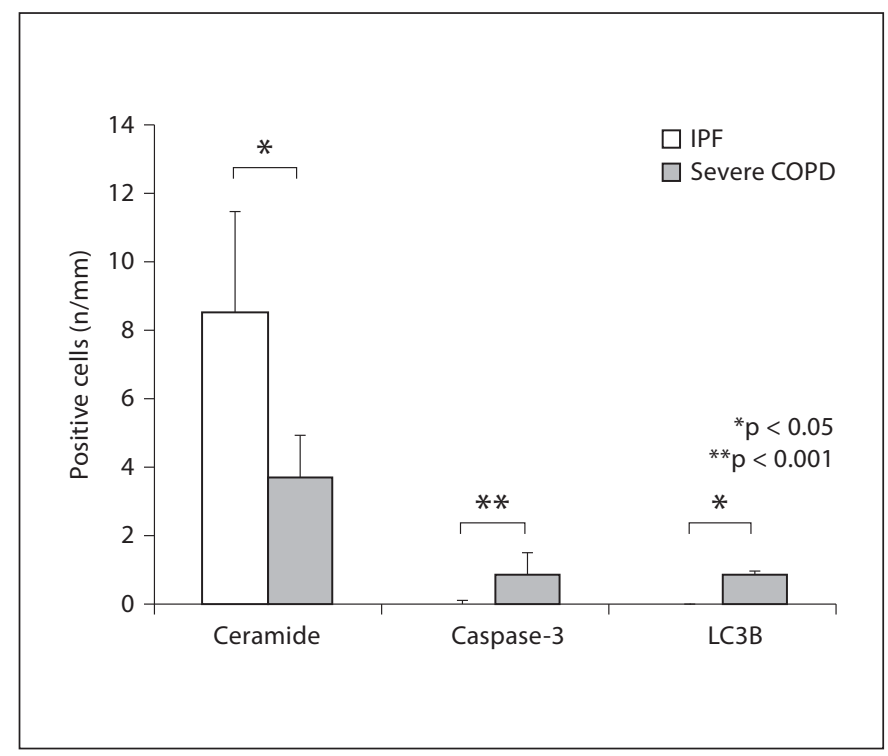

Fig. 4. Comparison of the expression of ceramide, cleaved caspase-3, and LC3B in cells of the alveolar wall between IPF subjects and severe COPD subjects.

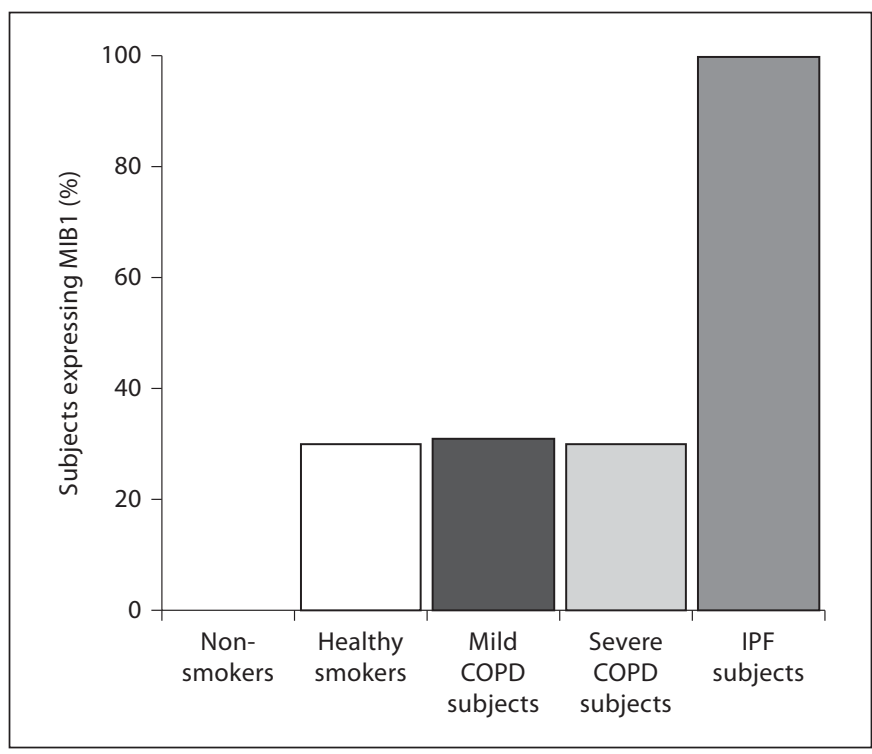

Fig. 5. Percentages of subjects expressing MIB1 in cells of the alveolar wall in IPF subjects, severe COPD subjects, mild/moderate COPD subjects, smokers without COPD, and nonsmokers. The percentage of subjects expressing MIB1 was different among the 4 groups $\left(\chi^{2} \mathrm{p}<0.01\right)$.

by increased apoptosis and autophagy of cells in the alveolar wall. These cellular processes were not counterbalanced by cell proliferation and were particularly evident in the most severe stage of COPD. Moreover, we were able to show that smoking per se did not influence expression of ceramide, apoptosis, and autophagy in the lung.

There is evidence that ceramide plays a role in the pathogenesis of cystic fibrosis [18], in the formation of pulmonary edema, and in pulmonary infections carried out by both bacteria (Pseudomonas aeruginosa, Neisseria gonorrhoeae, and Staphylococcus aureus) $[19,20]$ and viruses (rhinoviruses) [21]. A recent study by Petrusca et al. [22] suggests that excessive lung ceramides may amplify lung injury in emphysema. According to their results ceramides markedly impair the ability of alveolar macrophages to phagocyte apoptotic cells (efferocytosis). The pioneering study by Petrache et al. [2] investigated the role of ceramide in the pathogenesis of emphysema in animal models, corroborating these findings by evaluation of human lungs with emphysema. However, in that work patients were classified according to histological criteria rather than functional ones and their sample size was small. Furthermore, the actual degree of lung function impairment and smoking history were not reported. Our study therefore adds to the previous find- 
ings that ceramide expression is increased in the lungs of COPD patients, even with relatively mild disease and that activation of this pathway is not dependent on cigarette smoking only. The negative correlation between ceramide immunoreactivity and $\mathrm{PaO}_{2}$ suggests that this sphingolipidic second messenger is involved in processes that promote a ventilation-perfusion mismatch and that take place in peripheral lung. In contrast, ceramide expression is not related to the severity of COPD assessed by spirometry.

Apoptosis in the human lung in relation to development of COPD has been investigated by several groups with controversial results [23]. These studies are difficult to compare due to the differences in their definition of the study population, in the samples examined, and in the methods used to detect apoptosis. We chose caspase-3 as an apoptotic marker, as in the studies by Kasahara et al. [15] and Petrache et al. [2], because this molecule is a key executioner of apoptosis and is activated in both extrinsic (from membrane receptor signaling) and intrinsic (involving the mitochondria) apoptosis pathways [24]. Furthermore, it was demonstrated by Petrache et al. [2] that ceramide-induced airspace enlargement in a mouse model is dependent on caspase activation. The number of apoptotic cells in the alveolar wall of COPD patients was low, but our results are in line with those of Kasahara et al. [15].

Given that the majority of COPD patients are smokers, it was important to define whether lung apoptosis was related to smoking per se or if it was specifically associated with the development of airflow limitation. In our study, no significant differences in alveolar apoptosis between smokers without COPD and nonsmokers, or between current smokers and ex-smokers was observed. This is in agreement with the findings of Majo et al. [25], Kasahara et al. [15], and Yokohori et al. [14]. In particular, Hodge et al. [26] failed to demonstrate any difference between current smokers and ex-smokers.

It has been established [27] that a cross-talk exists between the underlying mechanisms that regulate apoptosis and autophagy pathways. Concurrent upregulation of both apoptosis and autophagy was observed in lung epithelial cells exposed to cigarette smoke [28, 29]. Evidence that cigarette smoke was associated with increased autophagy in the human lung was provided by Chen et al. [29]. However, they failed to demonstrate differences in autophagy between smokers with normal pulmonary function and COPD patients. The discrepancy with our results can be explained by the inability of Western blot analysis of lung homogenates to distinguish the relative contribution to autophagy between alveolar macrophages and lung parenchyma. Our finding of a correlation between LC3B and ceramide expression is consistent with the results of in vitro studies showing the ability of ceramide to trigger autophagy [4-6].

Since tissue homeostasis is the result of a complex balance between cell death and cell survival, it was important to relate ceramide expression not only to apoptosis and autophagy but also to lung cell proliferation. Only few studies have concurrently analyzed cell proliferation and apoptosis in the lung. Imai et al. [13] and Yokohori et al. [14] reported both increased apoptosis and cell proliferation in emphysematous patients. On the contrary, our research, similarly to Calabrese et al. [11], showed that apoptosis was not balanced by proliferation. The discrepancies between the different studies may be due to the different antibodies used to detect apoptosis, the type of patients involved in the respective studies, and the lung compartment examined.

Although a weak correlation between ceramide and caspase-3-positive cells was found in our study, the number of ceramide-positive cells greatly exceeded that of caspase-3-positive cells, suggesting that ceramide does not induce apoptosis in all cells. This lack of generally induced apoptosis may be caused by some cells producing both ceramide and sphingosine-1-phosphate (S1P), which promotes cell proliferation and may prevent ceramideinduced apoptosis [30]. Other mechanisms that protect cells from ceramide-induced apoptosis are the strong expression of acid ceramidase in alveolar macrophages [31] or the inhibition of caspase- 3 by interaction with aSMase in airway epithelial cells [32].

To evaluate whether ceramide upregulation was specific for the lung damage associated with COPD, we examined its expression in a different chronic lung disease, IPF. We found a prominent increase of this second messenger but evasion of both apoptosis and autophagy in the lung parenchyma of subjects with IPF. The latter finding is in line with the observation of a resistance to apoptosis of cells involved in the fibrotic process [33] and of decreased autophagy in IPF compared with COPD subjects [29].

Taking together these observations and our findings in COPD and IPF, it can be argued that ceramide expression probably represents a broader marker of lung damage. In contrast, the increased apoptosis and autophagy appear to be a more specific feature of the alteration in cell homeostasis of alveolar wall that occurs when the functional impairment of COPD becomes more severe. 


\section{Acknowledgements}

This study was supported by grants from the University of Padua (60A07-9885/09 CPDA105994/10) and by Associazione Ricerca Cura Asma (ARCA), Padova, Italy.

We thank K. Parker for editing the manuscript.

\section{Financial Disclosure and Conflicts of Interests}

None of the authors declares conflicts of interest related to this paper.

\section{References}

1 Cosio MG, Saetta M, Agusti A: Immunologic aspects of chronic obstructive pulmonary disease. N Engl J Med 2009;360:2445-2454.

-2 Petrache I, Natarajan V, Zhen L, Medler TR, Richter AT, Cho C, Hubbard WC, Berdyshev EV, Tuder RM: Ceramide upregulation causes pulmonary cell apoptosis and emphysema-like disease in mice. Nat Med 2005;11: 491-498.

3 Uhlig S, Gulbins E: Sphingolipids in the lungs. Am J Respir Crit Care Med 2008;178: 1100-1114.

-4 Lavieu G, Scarlatti F, Sala G, Levade T, Ghidoni R, Botti J, Codogno P: Is autophagy the key mechanism by which the sphingolipid rheostat controls the cell fate decision? Autophagy 2007;3:45-47.

5 Guenther GG, Peralta ER, Rosales KR, Wong SY, Siskind LJ, Edinger AL: Ceramide starves cells to death by downregulating nutrient transporter proteins. Proc Natl Acad Sci USA 2008;105:17402-17407.

-6 Pattingre S, Bauvy C, Levade T, Levine B, Codogno P: Ceramide-induced autophagy: to junk or to protect cells? Autophagy 2009; 5:558-560.

$>7$ Li DD, Wang LL, Deng R, Tang J, Shen Y, Guo JF, Wang Y, Xia LP, Feng GK, Liu QQ, Huang WL, Zeng YX, Zhu XF: The pivotal role of c-Jun NH2-terminal kinase-mediated Beclin 1 expression during anticancer agentsinduced autophagy in cancer cells. Oncogene 2009;28:886-898.

-8 Daido S, Kanzawa T, Yamamoto A, Takeuchi $\mathrm{H}$, Kondo Y, Kondo S: Pivotal role of the cell death factor BNIP3 in ceramide-induced autophagic cell death in malignant glioma cells. Cancer Res 2004;64:4286-4293.

9 Ryter SW, Chen ZH, Kim HP, Choi AM: Autophagy in chronic obstructive pulmonary disease: homeostatic or pathogenic mechanism? Autophagy 2009;5:235-237.

10 Sharafkhaneh A, Hanania NA, Kim V: Pathogenesis of emphysema: from the bench to the bedside. Proc Am Thorac Soc 2008;5:475-477.

-11 Calabrese F, Giacometti C, Beghe B, Rea F, Loy M, Zuin R, Marulli G, Baraldo S, Saetta M, Valente M: Marked alveolar apoptosis/ proliferation imbalance in end-stage emphysema. Respir Res 2005;6:14.

12 Segura-Valdez L, Pardo A, Gaxiola M, Uhal BD, Becerril C, Selman M: Upregulation of gelatinases $\mathrm{A}$ and $\mathrm{B}$, collagenases 1 and 2, and increased parenchymal cell death in COPD. Chest 2000;117:684-694.
13 Imai K, Mercer BA, Schulman LL, Sonett JR, D'Armiento JM: Correlation of lung surface area to apoptosis and proliferation in human emphysema. Eur Respir J 2005;25:250-258.

14 Yokohori N, Aoshiba K, Nagai A: Increased levels of cell death and proliferation in alveolar wall cells in patients with pulmonary emphysema. Chest 2004;125:626-632.

15 Kasahara Y, Tuder RM, Cool CD, Lynch DA, Flores SC, Voelkel NF: Endothelial cell death and decreased expression of vascular endothelial growth factor and vascular endothelial growth factor receptor 2 in emphysema. Am J Respir Crit Care Med 2001;163:737744 .

16 Global Initiative for Chronic Obstructive Lung Disease: Global strategy for the diagnosis, management and prevention of COPD. 2010. http://www.goldcopd.org.

17 Saetta M, Baraldo S, Corbino L, Turato G, Braccioni F, Rea F, Cavallesco G, Tropeano G, Mapp CE, Maestrelli P, Ciaccia A, Fabbri LM: CD8+ve cells in the lungs of smokers with chronic obstructive pulmonary disease. Am J Respir Crit Care Med 1999;160:711717.

18 Brodlie M, McKean MC, Johnson GE, Gray J, Fisher AJ, Corris PA, Lordan JL, Ward C: Ceramide is increased in the lower airway epithelium of people with advanced cystic fibrosis. Am J Respir Crit Care Med 2010;182: 369-375.

19 Grassmé H, Jendrossek V, Riehle A, von Kürthy G, Berger J, Schwarz H, Weller M, Kolesnick R, Gulbins E: Host defense against Pseudomonas aeruginosa requires ceramiderich membrane rafts. Nat Med 2003;9:322330.

20 Esen M, Schreiner B, Jendrossek V, Lang F, Fassbender K, Grassmé H, Gulbins E: Mechanisms of Staphylococcus aureus induced apoptosis of human endothelial cells. Apoptosis 2001;6:431-439.

21 Dreschers S, Franz P, Dumitru C, Wilker B, Jahnke K, Gulbins E: Infections with human rhinovirus induce the formation of distinct functional membrane domains. Cell Physiol Biochem 2007;20:241-254.

22 Petrusca DN, Gu Y, Adamowicz JJ, Rush NI, Hubbard WC, Smith PA, Berdyshev EV, Birukov KG, Lee CH, Tuder RM, Twigg HL 3rd, Vandivier RW, Petrache I: Sphingolipid-mediated inhibition of apoptotic cell clearance by alveolar macrophages. J Biol Chem 2010; 285:40322-40332.
23 Demedts IK, Demoor T, Bracke KR, Joos GF, Brusselle GG: Role of apoptosis in the pathogenesis of COPD and pulmonary emphysema. Respir Res 2006;7:53.

24 Henson PM, Tuder RM: Apoptosis in the lung: induction, clearance and detection. Am J Physiol Lung Cell Mol Physiol 2008; 294:L601-L611.

25 Majo J, Ghezzo H, Cosio MG: Lymphocyte population and apoptosis in the lungs of smokers and their relation to emphysema. Eur Respir J 2001;17:946-953.

-26 Hodge S, Hodge G, Holmes M, Reynolds PN: Increased airway epithelial and T-cell apoptosis in COPD remains despite smoking cessation. Eur Respir J 2005;25:447-454.

27 Maiuri MC, Zalckvar E, Kimchi A, Kroemer G: Self-eating and self-killing: crosstalk between autophagy and apoptosis. Nat Rev Mol Cell Biol. 2007;8:741-752.

28 Kim HP, Wang X, Chen ZH, Lee SJ, Huang MH, Wang Y, Ryter SW, Choi AM: Autophagic proteins regulate cigarette smoke-induced apoptosis: protective role of heme oxygenase-1. Autophagy 2008;4:887-895.

29 Chen ZH, Kim HP, Sciurba FC, Lee SJ, Feghali-Bostwick C, Stolz DB, Dhir R, Landreneau RJ, Schuchert MJ, Yousem SA, Nakahira K, Pilewski JM, Lee JS, Zhang Y, Ryter SW, Choi AM: Egr-1 regulates autophagy in cigarette smoke-induced chronic obstructive pulmonary disease. PLoS One 2008;3:e3316.

30 Xia P, Wang L, Gamble JR, Vadas MA: Activation of sphingosine kinase by tumor necrosis factor-alpha inhibits apoptosis in human endothelial cells. J Biol Chem 1999;274: 34499-34505.

- 31 Monick MM, Mallampalli RK, Bradford M, McCoy D, Gross TJ, Flaherty DM, Powers LS, Cameron K, Kelly S, Merrill AH Jr, Hunninghake GW: Cooperative prosurvival activity by ERK and Akt in human alveolar macrophages is dependent on high levels of acid ceramidase activity. J Immunol 2004; 173:123-135.

32 Castillo SS, Levy M, Wang C, Thaikoottathil JV, Khan E, Goldkorn T: Nitric oxide enhanced caspase- 3 and acidic sphingomyelinase interaction: a novel mechanism by which airway epithelial cells escape ceramide-induced apoptosis. Exp Cell Res 2007;313:816823.

33 Thannickal VJ, Horowitz JC: Evolving concepts of apoptosis in idiopathic pulmonary fibrosis. Proc Am Thorac Soc 2006;3:350-356. 